\title{
Half a century of ion-transport ATPases: the P- and V-type ATPases
}

\author{
Frank Wuytack
}

Published online: 26 July 2008

(C) Springer-Verlag 2008

This special issue focuses on two important types of ionmotive ATPases: P-type ATPases that are characterised by the formation of a phosphoprotein intermediate and V-type ATPases found in the diverse compartments belonging to the eukaryotic vacuolar system, which includes not only components of the secretory and endocytotic membrane system but also the plasma membrane.

The 1940s and the early 1950s were of pivotal importance for the newly emerging field of electrophysiology. In the course of this decennium, physiologists witnessed the gradual development of the concept of active transport of inorganic ions in cells. It became at that time, partly by the use of radioisotopes, gradually but undeniably clear that biological membranes do not act as barriers impermeable to ions like $\mathrm{Na}^{+}$or $\mathrm{K}^{+}$but that instead there exists a continuous transmembrane exchange of ions, and hence, that in order to ensure a steady state, cells had to actively move $\mathrm{Na}^{+}$and $\mathrm{K}^{+}$against concentration gradients. It was soon realised that the thus generated transmembrane electrochemical ion gradient can be used to drive other ions or non-ionic compounds uphill and that it allows the generation of electrical activity in the form of action potentials. However, it was also clear that preserving this transmembrane gradient, in face of the ongoing drain imposed by the various ion movements, requires the continuous input of energy. It is not surprising that evolution has pioneered many different types of active transport systems to counter these leaks. But the

F. Wuytack $(\bowtie)$

Department of Molecular Cell Biology,

Catholic University of Leuven,

Laboratory of $\mathrm{Ca}^{2+}$ transport ATPases,

Campus Gasthuisberg O/N1, bus 802, Herestraat 49,

3000 Leuven, Belgium

e-mail: frank.wuytack@med.kuleuven.be question remained how can chemical energy be harnessed to catalyse a vectorial transmembrane transport of ions?

It was Jens C. Skou in Denmark who, about 50 years ago in 1957, first pointed to an adenosine triphosphatase as the motor of this active transport system [1], a discovery that only 40 years later earned him the Nobel prize for Chemistry 1997: "for the first discovery of an ion-transporting enzyme, $\mathrm{Na}^{+}, \mathrm{K}^{+}$-ATPase" (see Nobel lecture at http://nobelprize.org/ nobel_prizes/chemistry/laureates/1997/skou-lecture.html and [2]).

The 1960s represent the decennium of the $\mathrm{Ca}^{2+}$-transporting ATPases. First, the $\mathrm{Ca}^{2+}$ transport ATPase from skeletal muscle sarcoplasmic reticulum (SERCA) and shortly thereafter that of erythrocyte plasma membrane (PMCA) joined the scene. The challenge became now to unravel the individual steps of the transport process. The phosphorylation of an aspartate residue in the ATPase was rapidly recognised as a necessary step in the catalytic cycle. The formation of this intermediate represents the hallmark of these ATPases, hence the name of this group of transporters, the P-type ATPases.

But not all transport ATPases make use of a phosphoprotein intermediate. The idea of the V-type ATPases took much more time to mature (see [3] for a review). The Vtype ATPases are now known to form an independent group of ion-transport ATPases using a molecular motor reminiscent of that found in the bacterial F-type ATPases. It took indeed another 30 years after the discovery of the $\mathrm{Na}^{+}, \mathrm{K}^{+}$ATPase before the V-type ATPases gained their status of independence.

This special issue is devoted to the P- and the V-type ATPases. Active ion transport by light-driven ion pumps of the kind found in bacteriorhodopsin or redox-driven pumps like the ones found in the mitochondrial or chloroplast electron transport chains are not addressed. Neither do we 
touch the evolutionary-related F-type ATPases that are more often involved in the generation of ATP rather than in its hydrolysis to fuel transmembrane transport.

Phylogenetically, the origin of both P- and V-type ATPases can be retraced to ancient prokaryote life forms, but it is in the frame of the far more elaborated structure of the eukaryotic cell, with its wealth of the most diverse intracellular membrane compartments, that these ATPases evolved into the highly specialised ion-motive ATPases.

In the year 2000, another leap forward of considerable importance for our understanding of the structure and function of the P-type ATPases was made when Toyoshima described the crystal structure of the $\mathrm{Ca}^{2+}$-transport ATPase from fast-skeletal muscle sarcoplasmic reticulum (SERCA1a) in its $\mathrm{Ca}^{2+}$-bound conformation [4]. This was only the first of a series of crystal structures, and it was soon followed by others where we could see the same enzyme immobilised in different forms each closely corresponding to a different conformation the enzyme could adopt throughout its catalytic cycle. For the first time, we could, as it were, see the enzyme moving. The advent of molecular biological techniques, which includes the extensive sitedirected mutagenesis of nearly all important residues of the ATPase, recent progress in proteomic analyses and the successes in protein structural analysis has provided so many novel insights in the evolution, structure, function and physiology of the transport ATPases that a special issue seems appropriate.

Of particular interest are the novel insights gained in the mechanochemistry of the P- and V-type ATPases that act as Brownian motors, channelling in an ATP-dependent manner random thermal motions into an ordered process, efficiently catalysing vectorial transport by a molecular mechanism that rewards appropriate motions and ignores unwanted ones (a true Darwinian principle).

But the physiological significance of the transport ATPases extends beyond that of merely transporting ions. Of particular interest is the rather recent realization that in some instances ion-motive ATPases appear to be co-opted for a function in cell signalling (examples of co-opted adaptation or exaptation). This is the case for some forms of $\mathrm{Na}^{+}, \mathrm{K}^{+}$-ATPases that are found to act as hormone receptor, mediating the effect of endogenous cardiotonic ouabain-like substances on protein tyrosine phosphorylation and subsequently on cell growth and by plasma membrane $\mathrm{Ca}^{2+}$ transport ATPase isoforms (PMCA) co-opted in cardiac NO signalling.

In this special issue, Buch-Pedersen et al. [5] elaborate on the recently published crystal structures and biochemical data published for some P-type ATPases and by comparison with information for bacteriorhodopsin and F-type ATPases propose a unifying mechanistic model for proton transport through biological membranes.
In the vast field of V-type ATPases, their role in the physiology of the diverse intracellular endomembrane systems and in pathology is addressed in two complementary reviews by Saroussi and Nelson [6] and by Hinton et al. [7], whereas Wassmer et al. [8] describe the remarkable complexity of the V-type ATPase system in the free-living protozoan Paramecium, which appears to express far more V-type ATPase genes than has been reported for any other species up to now.

Phylogenetically, the $\mathrm{Na}^{+}, \mathrm{K}^{+}$-ATPase and the $\mathrm{H}^{+}, \mathrm{K}^{+}$ATPases are closely related, and they represent the only Ptype ATPases that make use of a glycoprotein $\beta$ subunit. Shin et al. [9] review the gastric $\mathrm{H}^{+}, \mathrm{K}^{+}$-ATPase, whereas de Pont et al. [10] describe how the non-gastric $\mathrm{H}^{+}, \mathrm{K}^{+}$-ATPase can be used to explore the ouabain sensitivity of the different members of this subfamily, which all show either an intrinsic ouabain sensitivity or can be converted to an ouabain-sensitive form. The highly selective inhibition of $\mathrm{Na}^{+}, \mathrm{K}^{+}$-ATPase by ouabain and related cardiotonic steroids has always intrigued researchers. These inhibitors not only provided an interesting tool to explore the function of the ATPase but also led to one of the most successful pharmacological agents, the cardiac glycosides. It has however recently become clear that $\mathrm{Na}^{+}, \mathrm{K}^{+}$-ATPase can function as an important signal transducer responding to endogenously produced circulating steroids, which gives the $\mathrm{Na}^{+}, \mathrm{K}^{+}$-ATPase the status of hormone receptor. Li and Xie review this matter [11]. Although plants lack $\mathrm{Na}^{+}, \mathrm{K}^{+}$ATPase, they, together with fungi, possess a very elaborated system of P-type $\mathrm{H}^{+}$-ATPases with multiple functions. This is reviewed by Duby and Boutry [12].

Because $\mathrm{Ca}^{2+}$ is one of the evolutionary oldest and most widespread secondary messengers, ATPases that remove $\mathrm{Ca}^{2+}$ from the cytosol in order to halt the activation of various cellular activities are found in all types of cellular life forms. Brini [13] describes the complex family of plasma membrane $\mathrm{Ca}^{2+}$ transport ATPases (PMCA) that consists of four genes, but by means of alternative splicing, can create a bewildering variety of some 30 different splice variants. Most interestingly as reviewed by Cartwright et al. [14], in cardiac muscle, PMCA4 has become less involved in the bulk extrusion of $\mathrm{Ca}^{2+}$ but has instead acquired a novel function as modulator of the nitric oxide signal transduction pathways, thereby affecting muscle hypertrophy. Also, the $\mathrm{Ca}^{2+}$-transport ATPases of the endoplasmic reticulum (SERCAs) are involved in controlling cell growth and differentiation as described by Lipskaia et al. [15] or apoptosis as treated by Vafiadaka et al. [16]. An emerging new theme in the study of SERCA pumps is related to its high sensitivity to damage by reactive oxygen/nitrogen species. This largely ignored characteristic is reviewed by Bigelow [17].

It is clear, as is illustrated in this special issue, that the field of P- and V-ATPases is now rapidly expanding and 
that the role of these molecules goes far beyond this of mere transporters. Various new types of post-translational modifications and interactions with protein or lipid regulators emerged recently and will certainly be discovered in the near future. Integrating these in the delicate but at the same time robust network that a living system represents will be one of the main future challenges we are facing.

\section{References}

1. Skou JC (1957) The influence of some cations on an adenosine triphosphatase from peripheral nerves. Biochim Biophys Acta 23:394-401

2. Skou JC (2003) The identification of the sodium-potassium pump. Nobel Lecture, December 8, 1997. In: Grenthe I (ed) Nobel lectures chemistry 1996-2000. World Scientific, Singapore, pp 179-194

3. Beyenbach KW, Wieczorek H (2006) The V-type $\mathrm{H}^{+}$ATPase: molecular structure and function, physiological roles and regulation. J Exp Biol 209:557-589

4. Toyoshima C, Nakasako M, Nomura H, Ogawa H (2000) Crystal structure of the calcium pump of sarcoplasmic reticulum at $2.6 \AA$ resolution. Nature 405:647-655

5. Buch-Pedersen MJ, Pedersen BP, Veierskov B, Nissen P, Palmgren MG (2008) Protons and how they are transported by proton pumps. Pflugers Arch. 2008 May 6. (in press)

6. Saroussi S, Nelson N (2008) Vacuolar $\mathrm{H}^{+}$-ATPase-an enzyme for all seasons. Pflugers Arch. 2008 Mar 5. (in press)
7. Hinton A, Bond S, Forgac M (2008) V-ATPase functions in normal and disease processes. Pflugers Arch. 2007 Nov 20. (in press)

8. Wassmer T, Sehring IM, Kissmehl R, Plattner H (2008) The VATPase in Paramecium: functional specialization by multiple gene isoforms. Pflugers Arch. 2008 Jan 29. (in press)

9. Shin JM, Munson K, Vagin O, Sachs G (2008) The gastric HKATPase: structure, function, and inhibition. Pflugers Arch. 2008 Jun 6. (in press)

10. De Pont JJ, Swarts HG, Karawajczyk A, Schaftenaar G, Willems PH, Koenderink JB (2008) The non-gastric H,K-ATPase as a tool to study the ouabain-binding site in Na,K-ATPase. Pflugers Arch. 2008 Mar 7. (in press)

11. Li Z, Xie Z (2008) The Na/K-ATPase/Src complex and cardiotonic steroid-activated protein kinase cascades. Pflugers Arch. 2008 Feb 19. (in press)

12. Duby G, Boutry M (2008) The plant plasma membrane proton pump ATPase: a highly regulated P-type ATPase with multiple physiological roles. Pflugers Arch. 2008 Jan 29. (in press)

13. Brini M (2008). Plasma membrane $\mathrm{Ca}^{2+}$-ATPase: from a housekeeping function to a versatile signaling role. Pflugers Arch. 2008 Jun 12. (in press)

14. Cartwright EJ, Oceandy D, Neyses L (2008) Physiological implications of the interaction between the plasma membrane calcium pump and nNOS. Pflugers Arch. 2008 Jan 29. (in press)

15. Lipskaia L, Hulot JS, Lompré AM (2008) Role of sarco/ endoplasmic reticulum calcium content and calcium ATPase activity in the control of cell growth and proliferation. Pflugers Arch. 2008 Jan 11. (in press)

16. Vafiadaki E, Papalouka V, Arvanitis DA, Kranias EG, Sanoudou D (2008) The role of SERCA2a/PLN complex, $\mathrm{Ca}^{2+}$ homeostasis, and anti-apoptotic proteins in determining cell fate. Pflugers Arch. 2008 Apr 16. (in press)

17. Bigelow DJ (2008) Nitrotyrosine-modified SERCA2: a cellular sensor of reactive nitrogen species. Pflugers Arch. 2008 Jan 3. (in press) 